\title{
Correction to: Advanced Nanomaterials and Their Functionalization in Clinical Endodontics
}

\author{
Hend Mahmoud Abou El Nasr and Makbule Bilge Akbulut
}

\section{Correction to:}

Chapter 3 in: R. S. Chaughule (ed.), Dental Applications of Nanotechnology, https://doi.org/10.1007/978-3-319-97634-1_3

The original version of the book was inadvertently published with incorrect co-author name, which should be corrected to read as "Makbule Bilge Akbulut" in Chapter 3. The correction chapter and the book have been now updated with the change.

The updated online version of this chapter can be found at https://doi.org/10.1007/978-3-319-97634-1_3 